\title{
ENDODONTIC TREATMENT OF LOWER LATERAL INCISOR WITH THREE ROOT CANALS - CASE REPORT
}

\author{
Tzvetelina G. Gueorgieva ${ }^{1}$, Rahaf A. Mohamed ${ }^{2}$ \\ 1) Department of Conservative Dentistry, Faculty of Dental Medicine, \\ 2) Student at Faculty of Dental Medicine - Sofia \\ Medical University Sofia, Bulgaria.
}

\begin{abstract}
SUMMARY
The main goal of endodontic treatment is the correct diagnosis, optimal mechanical and chemical preparation and three-dimensional obturation of the root canal. Reasons for endodontic failure can be variations in the anatomy of the teeth - the presence of additional root canals, lateral canals, intricate anatomy of the apical delta. Very often lower incisors occurred more than one root canal. Many dentists are treating this group of teeth under general assumption, that they possess single canal. The purpose of this article is to present the treatment of lower lateral incisor with three root canals and discuss the signs of the existence of additional root canals.
\end{abstract}

Key words: endodontic treatment, additional root canals

\section{INTRODUCTION:}

The main goal of endodontic treatment is the correct diagnosis, optimal mechanical and chemical preparation and three-dimensional obturation of the root canal. Reasons for endodontic failure can be variations in the anatomy of the teeth - the presence of additional root canals, lateral canals, intricate anatomy of the apical delta. Very often lower incisors occurred with more than one root canal. $(1,2,5,6)$. The additional root canals are difficult to detect due to the inclination of the tooth crown and lingual position of the cavity for endodontic access. Often one of the canals remains untreated. This means that for successful endodontic treatment is necessary to also know the normal anatomy of the teeth, but also possible variations in morphology. Frank J Vertucci (1974) classifies the configuration of root canals of the lower incisors in 4 types: $(3,4,7)$.

Type 1 - The existence of one root canal

Type 2 - The existence of two separate root canals that merge into one

Type 3 -The existence of one root canal, which is divided into two in the middle of root and in apical part merged again in one

Type 4 -The existence of two separate root canals

\section{CASE REPORT:}

A 63 year-old female reported the Faculty of Dental Medicine - Sofia, Department of Conservative Dentistry with a complaint of pain in the lower left second incisor. There was a history of periodic and spontaneous tooth discomfort. The patient reports of previous treatment of the tooth. From clinical examination we find that the tooth has a destroyed clinical crown and is sensitive to percussion.. From diagnostic radiography (Fig. 1) it appears that the tooth has a badly performed endodontic treatment. There is a separation in the shadow of the root canal of the tooth, which means that there may be more than one root canal. The treatment plan for retreatment include: development of endodontic access and discovery of all root canals; remove old sealer, mechanical and chemical preparation of root canals and their three-dimensional obturation; restoration of tooth with radicular pin and plastic material and subsequently elaboration of crowns.

Treatment begins with removal of carious tooth structure. Root canal, which was endodontical treated was located vestibular. Therefore, in order to find the additional root canals we expanded cavity for endodontic access in vestibular-lingual direction. We found two root canal located one behind the other (Fig. 2.). A second X-ray is taken to determine the working length (Fig. 3) - vestibular root canal - $17 \mathrm{~mm}$, central root canal $17 \mathrm{~mm}$ and lingual root canal $16 \mathrm{~mm}$. It can be seen that the three root canals merged into one in apical direction. The root canals were prepared with the help of hand K files with Step-back technique up to 30 number at working lenght, after each insturment the root canals were irrigated with hydrogen peroxide $(3 \%)$ and sodium hypochlorite $(0.5 \%)$. The root canals were obturated with gutta-percha and Endomethasone N (Septodont) by with central-pin technique. After that we performed another x-ray to control the root canal obturation (Fig. 4 and 5). One week later the tooth is built up with radicular pin and is prepare to be restore with full crown. 


\section{DISCUSSION:}

For optimal performance of endodontic treatment is necessary correct diagnosis, full mechanical and chemical cleaning and hermetic root canal obturation in the whole volume. The presence of additional untreated root canals are a major cause of endodontic failure. This leads to incomplete removal of the causes of inflammation of the pulp chamber. In the lower incisors can often exist one or two additional root canals, which, if not treated could be reason for failure. It is necessary to know the anatomy of individual teeth and group of teeth and precisely and correctly to interpret diagnostic radiographs. Sometimes it is necessary to make radiographs in different projections to find out additional root canal. It is important for the proper performance of endodontic treatment the correct preparation of the cavity for endodontic access. The cavity for endodontic access in the lower incisors can be expanded in the vestibular-lingual direction, in order not to be missed the additional root canals.

\section{CONCLUSION:}

In the morphology of the pulp chamber of lower incisors can often be found deviations in the number and the configuration of root canals. For successful endodontic treatment is important a knowledge of the anatomy of the teeth, perform additional radiographs in different projections and modify the cavity for endodontic access, which would facilitate the discovery of additional root canals.

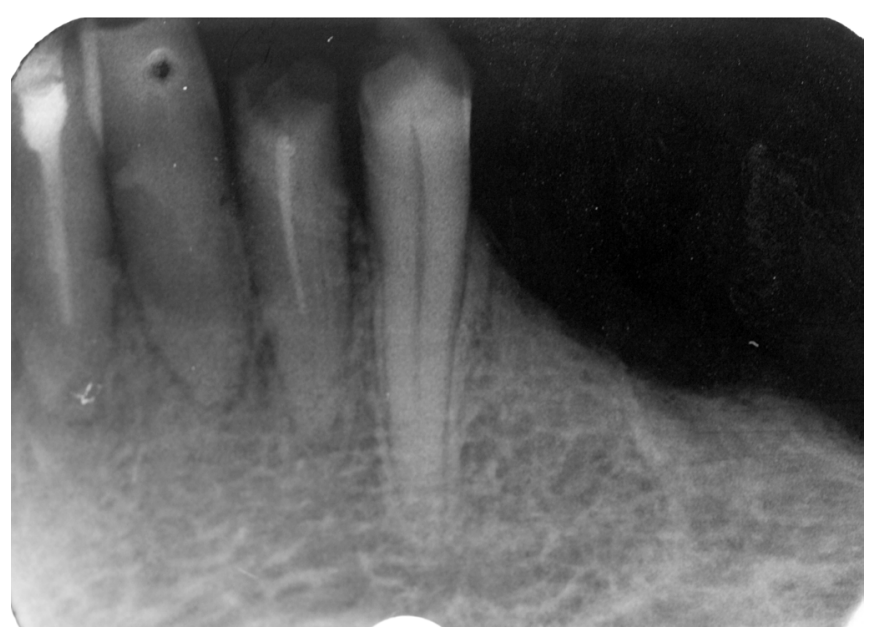

Fig. 1. - Diagnostic X-ray, tooth 32

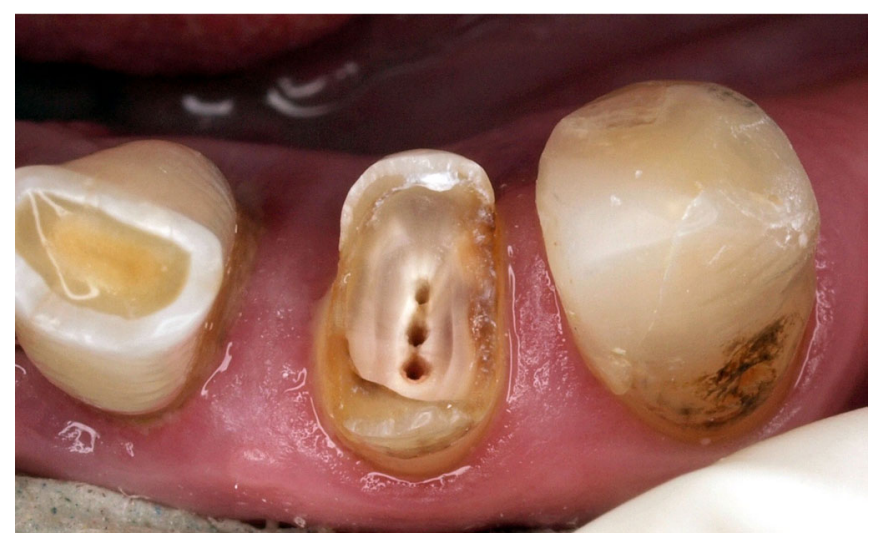

Fig. 2. Disclosure of three orifices of tooth 32

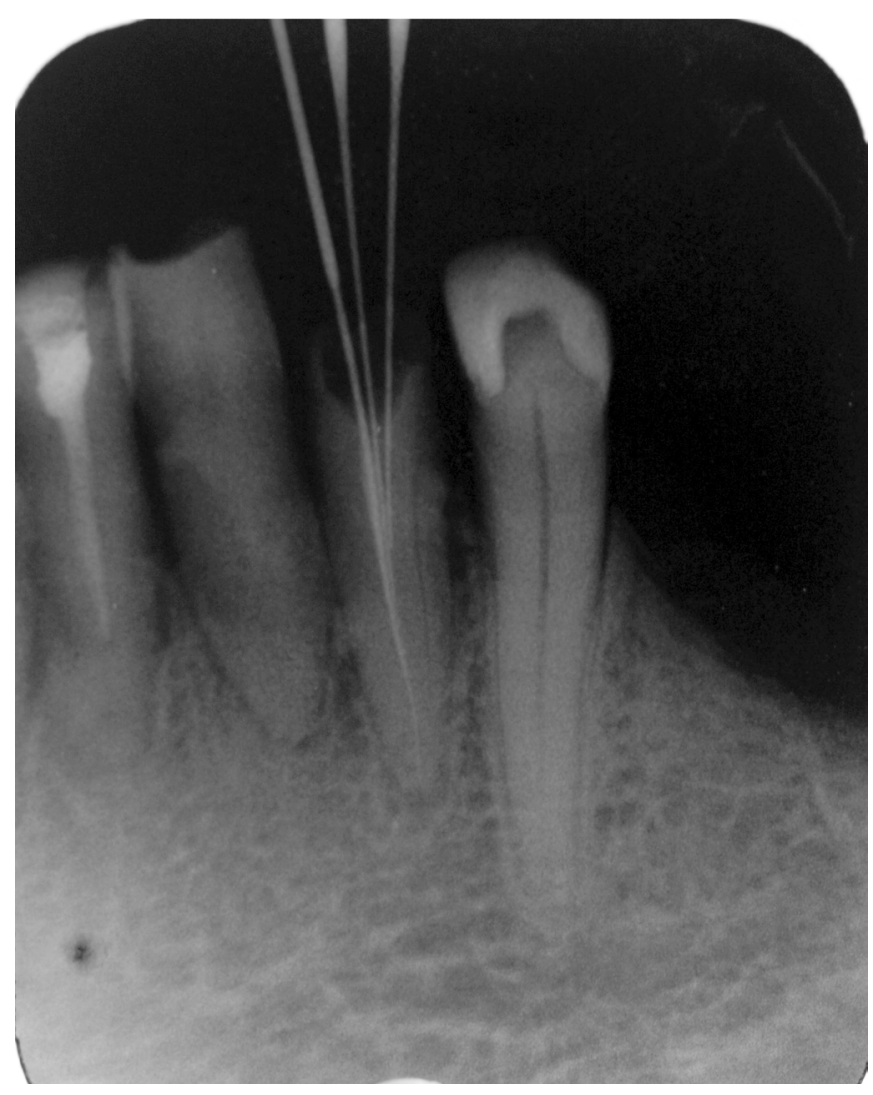

Fig. 3. Determination of working length of tooth 32 

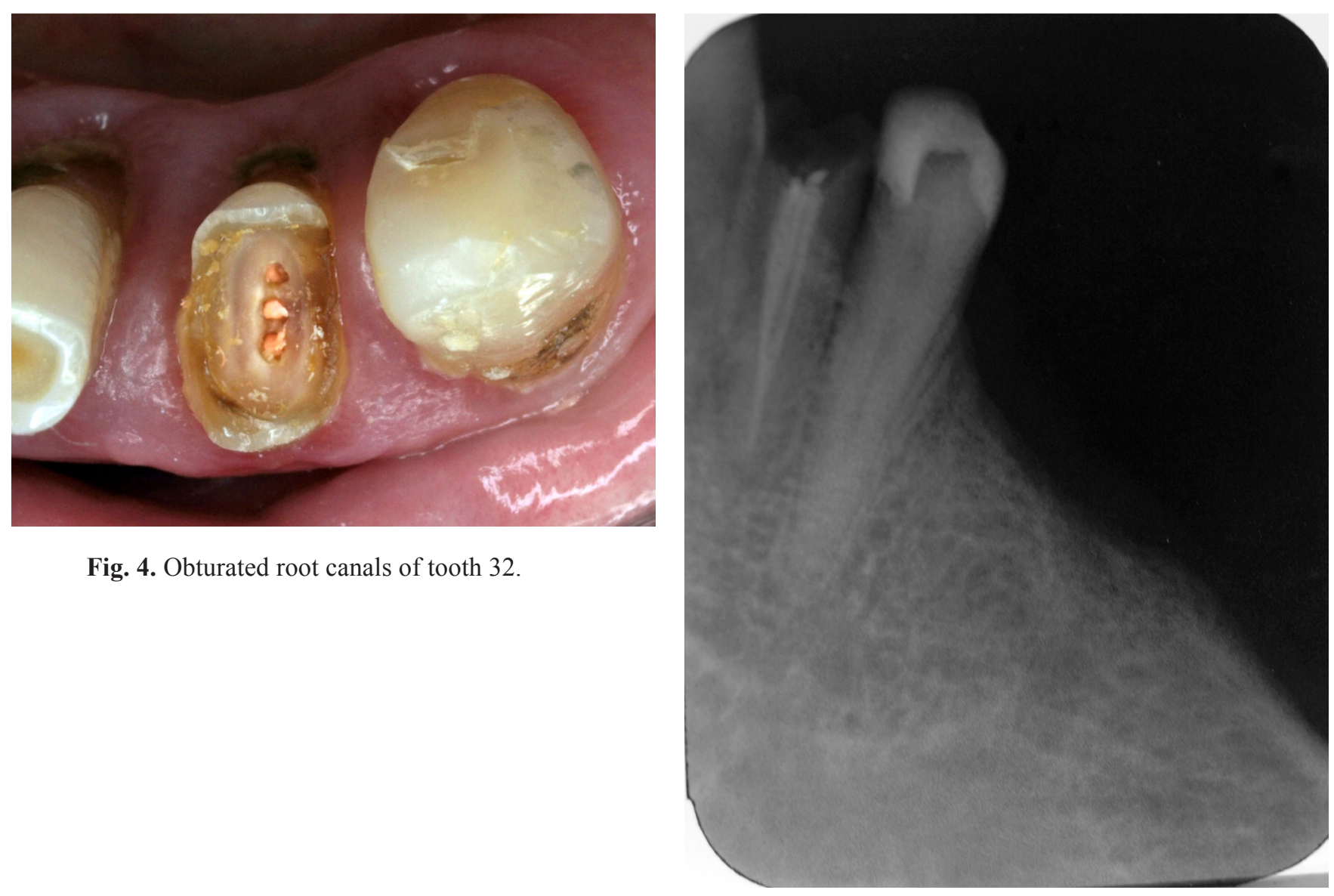

Fig. 4. Obturated root canals of tooth 32.

Fig. 5. X-ray after root canal obturation of tooth 32 .

\section{REFERENCES:}

1. Bellizzi R, Hartwell G. Clinical investigation of in vivo endodontically treated mandibular anterior teeth. $J$ Endod. 1983,Jun;9(6):246-8.[PubMed]

2. Benjamin KA, Dowson J. Incidence of two root canals in human mandibular incisor teeth. Oral Surg Oral Med Oral Pathol. 1974 Jul;38(1):122-6. [PubMed]

3. Hema BS, Chandu GS.
Endodontic management of type II canal mandibular incisiors: a case report. Indian J Stomatol. 2011 Jul;2(4):270-272.

4. Madeira MC, Hetem S. Incidence of bifurcations in mandibular incisors. Oral Surg Oral Med Oral Pathol. 1973 Oct;36(4):589-591. [PubMed]

5. Rankine-Willson RW, Henry P. The bifurcated root canals in lower anterior teeth. $J$ Am Dent Assoc. 1965 May;70:1162-5. [PubMed]

6 . Vertucci FJ. Root canal anatomy of the mandibular anterior teeth. $J \mathrm{Am}$ Dent Assoc. 1974 Aug; 89(2):369-71. [PubMed]

7. Vertucci FJ. Root canal anatomy of the human permanent teeth. Oral Surg Oral Med Oral Pathol. 1984 Nov;58(5):589-599. [PubMed]

Address for correspondence:

Dr. Tzvetelina G. Gueorgieva,

Department of Conservative dentistry, Faculty of Dental Medicine,

Medical University - Sofia

1, St. Georgi Sofiiski boul., 1000 Sofia, Bulgaria

E-mail: cvettyg@gmail.com; 